\title{
Self-lubricity of $\mathrm{WSe}_{\mathrm{x}}$ nanocomposite coatings
}

\author{
S. Domínguez-Meister ${ }^{\mathrm{a}}$, M. Conte ${ }^{\mathrm{b}, \ddagger}$, A. Igartua ${ }^{\mathrm{b}}$, T.C. Rojas ${ }^{\mathrm{a}}$, J.C. Sánchez-López ${ }^{\mathrm{a}, *}$ \\ ${ }^{a}$ Instituto de Ciencia de Materiales de Sevilla, Avda. Américo Vespucio 49, 41092 \\ Sevilla, Spain \\ ${ }^{b}$ IK4-Tekniker, Polo Tecnológico de Guipúzcoa, Calle Iñaki Goenaga 5, 20600 Eibar, \\ Spain
}

*Contact e-mail: jcslopez@icmse.csic.es

${ }^{\ddagger}$ Current address: Anton Paar TriTec SA, Rue de la Gare 4, 2034 Peseux, Switzerland and Empa, Laboratory for Mechanics of Materials and Nanostructures, Feuerwerkstrasse 39, 3602 Thun, Switzerland

Keywords: tungsten selenide, Raman, electron microscopy, nano-structure, friction

\begin{abstract}
Transition metal chalcogenides with lamellar structure are known for their use in tribological applications although limited to vacuum due to their easy degradation in presence of oxygen and/or moisture. Here we present a tailored $\mathrm{WSe}_{\mathrm{x}}$ coating with low friction (0.07) and low wear rates $\left(3 \times 10^{-7} \mathrm{~mm}^{3} \mathrm{Nm}^{-1}\right)$ even in ambient air. To understand the low friction behaviour and lower chemical reactivity a tribological study is carried out in a high vacuum tribometer under variable pressures (atmospheric pressure to $\left.10^{-8} \mathrm{mbar}\right)$. A detailed investigation of the film nanostructure and composition by advanced transmission electron microscopy techniques with nanoscale resolution determined that the topmost layer is formed by nanocrystals of $\mathrm{WSe}_{2}$ embedded in an amorphous matrix richer in $\mathrm{W}, \mathrm{a}-\mathrm{W}(\mathrm{Se})$. After the friction test, an increased crystalline order and orientation of $\mathrm{WSe}_{2}$ lamellas along the sliding direction
\end{abstract}


have been observed in the interfacial region. Based on high angle annular dark field, scanning transmission electron microscopy and energy dispersive X-ray analysis, the release of $\mathrm{W}$ atoms from the interstitial basal planes of the a-W(Se) phase is proposed. These $\mathrm{W}$ atoms reaching the surface, play a sacrificial role preventing the lubricant $\mathrm{WSe}_{2}$ phase from oxidation. The increase of the $\mathrm{WSe}_{2}$ crystalline order and the buffer effect of $\mathrm{W}$ capturing oxygen atoms would explain the enhanced chemical and tribological response of this designed nanocomposite material.

\section{INTRODUCTION}

Smart surface engineering and coating technologies have improved over the years and now they can be used to meet the increasingly stringent and multi-functional applications needs of operational conditions of engine systems, advanced machining and manufacturing applications. ${ }^{1-4}$ Specifically, by designing and using smart tribological coating architectures, researchers have already pioneered the development of a variety of nano-composite and/or nano-structured coatings providing longer

lifetime and enhanced performance under variable working conditions. ${ }^{5,6}$ Poor or inefficient lubrication may result in high friction and wear losses, which can, in turn, adversely affect the fuel economy and durability of engines and tools. When used on a lubricated surface, a solid lubricant film may substantially increase the load-bearing capacity and lubricity of that surface by shearing easily. If liquid lubricant fails, solid lubricant can carry the load and prevent direct metal-to-metal contact. Lamellar solid lubricants (such as $\mathrm{MoS}_{2}$, graphite, hexagonal boron nitride) and soft metals (such as $\mathrm{Ag}, \mathrm{Au}, \mathrm{In}, \mathrm{Sn}, \mathrm{Pb})$ in the form of thin films or added to oils and greases in the form of nanoparticles can increase their anti-friction and anti-wear capabilities. ${ }^{7-9}$ 
Transition metal $(\mathrm{TM})$ sulfides $\left(\mathrm{MoS}_{2}, \mathrm{WS}_{2}\right)$ are well known for their lubricant properties. The low friction is attributed to their anisotropic layered structure, where the adjacent lamellae with strong covalent bonding interact through relatively weak Van der Waals forces. The orientation of the basal planes parallel to the surface in contact provides the easy inter- and intra-crystalline slipping. The sliding process induces a preferred orientation in the contacting layer, so that (002)-oriented transfer layer and basally oriented sulfide wear tracks are generated during the steady state. ${ }^{10}$ However, their application is limited to vacuum or dry environments because of the sensitivity to humid air. ${ }^{11}$ When the S-TM-S planes are oriented perpendicular to the substrate (that is, in the (100) orientation), the exposed edges of these atomic planes are exposed to the atmosphere and oxidized. Improving this tribological performance has been an active area of study particularly for space components that require testing or storage periods on Earth. Increased wear resistance and load bearing capacity has been reported by alloying with metals $(\mathrm{Ti}, \mathrm{Au}, \mathrm{Pb}, \mathrm{Ni}, \mathrm{Cr})^{12}$ or non-metals $(\mathrm{N} \text { or carbon })^{13}$. As an alternative, nanoscale multilayer (metal/MoS${ }_{2}{ }^{14}, \mathrm{MoS}_{2} / \mathrm{WS}_{2}{ }^{15}$ ) or composite films, with mixed hard and soft lubricant phases $\left(\mathrm{MoS}_{2} / \mathrm{WC}^{16} ; \mathrm{WS}_{2} / \mathrm{WC} / \mathrm{DLC}^{14} ; \mathrm{TiN} / \mathrm{MoS}_{\mathrm{x}}{ }^{18}\right.$; $\mathrm{TiCrBN} / \mathrm{WSe}_{\mathrm{x}}{ }^{19} ; \mathrm{WS}_{2} / \mathrm{ZnO}^{20} ; \mathrm{TiSiN} / \mathrm{WS}_{2}{ }^{21}$ ) have been also studied in the past. One of the most studied systems have been the transition metal dichalcogenides mixed with carbon by Polcar \& Cavaleiro by co-sputtering of the metal sulfides or selenides with graphite. $^{22,23}$

Metal selenides are less studied than sulfides although they have been also object of intense study due to their self-lubricant properties, ${ }^{24-29}$ applications in photovoltaics $^{30}$ or ultralow thermal conductivity ${ }^{31}$. They have similar layered crystal structure formed by Se-W-Se platelets although with higher axial ratio of lattice parameters which facilitates relative motion between layers ${ }^{32}$. They exhibit lower 
average friction coefficients ${ }^{22}$ and have demonstrated to be less sensitive to moisture in the environment. ${ }^{22,24,26}$ As a metal, $\mathrm{W}$ is preferred to $\mathrm{Mo}$, as $\mathrm{WO}_{3}$ is slightly more protective than $\mathrm{MoO}_{3}$ and provides lower friction coefficient (0.2-0.3 vs. 0.5-0.6, respectively $)^{33}$. They show similar drawbacks than their metal sulfides: low hardness, low adhesion to the substrate and lacking bearing capacity as well as high wear rate and friction coefficient in humid air. The influence of oxygen in the alteration of the friction mechanism is still controversial. The formation of a surface tribolayer by reorientation of the basal planes parallel to the surface would avoid the combination of the oxygen with the dangling bonds ${ }^{34}$.

In previous work, a tailored microstructure of a $\mathrm{WSe}_{\mathrm{x}}$ coating was deposited by non-reactive magnetron sputtering with argon using a $\mathrm{WSe}_{2}$ target, and a timedependent d.c.-pulsed bias. The microstructure was formed by three different sub-layers and a variable Se/W ratio along its growing direction (W rich on bottom and Se rich on top). This designed engineered architecture was responsible for good mechanical properties $(\mathrm{H}=5 \mathrm{GPa}$; $\mathrm{E}=90 \mathrm{GPa})$, low friction $(0.07)$ and low wear rates in ambient air $\left(3 \times 10^{-7} \mathrm{~mm}^{3} \mathrm{Nm}^{-1}\right) .{ }^{35}$ In this paper the tribological properties are measured in the high vacuum tribometer CATRI (C) IK4-TEKNIKER under variable ambient pressures (atmospheric pressure to $10^{-8}$ mbar). A particular nanostructural study by advanced transmission electron microscopy and analytical tools with nanometric resolution will enable to determine the friction mechanism under variable surrounding atmosphere. The improved performance of this tailored $\mathrm{WSe}_{\mathrm{x}}$ lubricant material is highlighted and discussed for tribological applications.

\section{EXPERIMENTAL SECTION}


Tribological tests have been carried out in the CATRI (C) IK4-TEKNIKER HV tribometer with a 3-mm 100Cr6 ball with variable surrounding atmosphere (atmospheric pressure to $10^{-8}$ mbar). The $\mathrm{WSe}_{\mathrm{x}}$ samples deposited onto a silicon substrate were supported in a vertical oscillating rod that moves in the sliding direction. A mechanical action is exerted to the sample by a static pin mounted at the end of a two positioning stage $(\mathrm{Y}, \mathrm{Z})$ device. The Z-stage is used to apply the normal load while the Y-stage is used to carry out multiple parallel measurements on the flat sample. Reciprocating tests were done at $1 \mathrm{~N}$ of applied load (maximum contact pressure of $\sim 1$ $\mathrm{GPa}$ ), stroke length of $2 \mathrm{~mm}$, and $2 \mathrm{~mm} / \mathrm{s}$ of linear speed during 1250 cycles. Long duration tests were performed in a ball-on-disk CSM tribometer using a 6-mm 100Cr6 ball at $5 \mathrm{~cm} / \mathrm{s}$ of sliding speed and $2 \mathrm{~N}$ of applied load during 150000 and 250000 cycles.

Raman spectra measurements $\left(200-1800 \mathrm{~cm}^{-1}\right)$ were carried out with a LabRAM (Horiba Jobin Yvon) spectrometer equipped with a true confocal microscope, a chargecoupled device detector and a He-Ne laser (532 nm) working at $2.5 \mathrm{~mW}$ to avoid sample damaging. All the samples were analyzed with $100 \mathrm{~s}$ exposure times and aperture openings of $100 \mu \mathrm{m}$ using a $100 \times$ magnification.

For the advanced microstructural characterization and elucidation of the friction mechanism, cross-sectional specimens prepared by FIB were investigated before and after the friction test using a FEI TECNAI G2 F30 S-Twin high resolution transmission electron microscope operating at $300 \mathrm{kV}$ operated at $300 \mathrm{kV}$, with $0.2 \mathrm{~nm}$ point resolution, equipped with a HAADF detector with $0.16 \mathrm{~nm}$ point resolution from Fischione Instruments, and a X-Max EDX detector from Oxford.

\section{RESULTS AND DISCUSION}


3.1 Tribological test results. Previous publications on tungsten diselenides have reported a better moisture resistance and chemical stability than metal sulfides $\left(\mathrm{MoS}_{2}\right.$ or $\mathrm{WS}_{2}$ ). In our previous work ${ }^{35}$ we found an excellent low friction behavior (below 0.1 ) either in air $(\mathrm{RH}=30-40 \%)$ or dry nitrogen $(\mathrm{RH}<7 \%)$. In order to complete the study of the dependence of the tribological properties with the surrounding media, further tests were performed in variable controlled atmosphere inside a high-vacuum (HV) tribometer. Figure 1 displays the friction curves obtained in atmospheric pressure, and two $\mathrm{HV}$ values $\left(4 \times 10^{-7}\right.$ and $3.5 \times 10^{-8}$ mbar $), \mathrm{HV}-1$ and $\mathrm{HV}-2$, respectively. In dry ambient, the friction coefficient decreases and steadies around 0.04 while in air, the value is higher although below 0.1 as commented previously.

Figure 2 reports the evolution of the friction coefficient while changing the atmospheric pressure in a dynamic way from HV to atmospheric, and then back to HV. It can be observed that the friction coefficient does not alter significantly despite of the drastic change of the surrounding media. The average friction coefficient obtained for the entire test is 0.05 . The lack of dependence of the tribological response for this type of material represents a significant improvement in respect to DLC and $\mathrm{MoS}_{2}$ conventional lubricant solid materials. In these cases, the presence of oxygen or water molecules leads to a degradation of the low friction conditions and may cause final failure $^{8,36}$. Although the main use of this layered materials as lubricants is under vacuum, this higher chemical stability of the tungsten selenide appears advantageous for situations where the films are exposed to air (during handling or storage) before final application.

According to the friction curves shown in Figure 1 for $\mathrm{HV}-1$ and $\mathrm{HV}-2$, a running-in period is observed for 200-300 cycles where friction rises up to a maximum level of 0.07 , before a sudden decrease and stabilization around 0.04 . These running-in 
stages are usually associated to removal of surface asperities, native oxide layers and transfer film build-up. With the aim of dilucidating the influence of ball counterface modification, an interrupted friction test was carried out, stopping at the top of the friction curve. Then, the sample position was changed and a new test was begun using the same ball to slide onto new fresh surface. The obtained results are shown in Figure 3. The friction coefficient follows exactly the same trend, displaying a transition period before stabilization. This result proves the needs of film surface modification in order to achieve the ultra-low friction regime.

With the aim of determining the life performance and wear rate of the developed lubricant for the foreseen tribological application, a long duration test was carried out in dry nitrogen atmosphere at higher linear speeds in a rotative pin-on-disk using M2 steel substrates. Figure 4 reports the friction evolution until reaching the film failure. This process occurred at about $2 \times 10^{5}$ cycles. Up to this moment very stable and steady-state regime is denoted. Measurement of the film wear track at this point reveals a wear depth of around $450 \mathrm{~nm}$. This value is higher than the thickness of the top lubricant region (I) ranged in $300 \mathrm{~nm}$ indicating that the change of tribological behavior is associated to the consumption of the lubricant material. With the aim of establishing the film wear rate a shorter test of $1.5 \times 10^{5}$ cycles was carried out. The friction coefficient remained stable and constant enabling the estimation of the film wear rate. The obtained value was $2 \times 10^{-8} \mathrm{~mm}^{3} / \mathrm{Nm}$ and the wear track depth was found to be about $185 \mathrm{~nm}$ confirming that the lubricant layer has not yet worn through.

3.2 Nanostructure and chemical composition. To have an insight on the solid lubricant mechanism and their dependency upon the ambient environment, the sample was studied from a structural and compositional point of view using high resolution 
transmission electron microscopy (HRTEM), high angle annular dark field (HAADF) and energy-dispersive X-ray spectroscopy working in scanning TEM mode (STEM), before and after the friction test in ambient air. A representative cross-section HAADFSTEM or Z-contrast image of the coating is depicted in Figure 5a where the signal intensity is proportional to $\mathrm{Z}^{3 / 2} \cdot t$ (where $\mathrm{Z}$ is the atomic number and $t$ is the sample thickness). Three main regions with different intensity are observed (labelled as I, II and III). In the intermediate region (II) a subdivision into three thinner layers is also found. Figure 5b plots the intensity profile of the HAADF signal along the marked line in Figure $5 \mathrm{a}$ as well as the atomic percentage of $\mathrm{W}$ and Se atoms obtained from the EDX spectra measured using a probe of less than $1 \mathrm{~nm}$. The bottom layer (III) is mainly composed of metallic $\mathrm{W}$ and the Se content is sequentially increasing along the second and third regions up to a maximum in the topmost layer. These changes account for the different intensity observed in the HAAD-STEM image (cf. Figure 5a). The average $\mathrm{Se} / \mathrm{W}$ ratios obtained by integrating the EDX spectra in the different regions are depicted in Figure 5c. This layered structure is consequence of the modulated pulsed bias applied to the substrate during film growth. Thus, Figure 5d displays the variation of the applied negative voltage going from 55 to $0 \mathrm{~V}$ in steps of $5 \mathrm{~V} / \mathrm{h}$. Thanks to this sequence a modulation in chemical composition and mechanical properties can be achieved as demonstrated in our previous publication. ${ }^{35}$ This tailored architecture is providing the coating with good adhesion to the substrate, film density, mechanical support and chemical composition for the foreseen tribological application.

Figure 6a presents a higher magnification Z-contrast image of the region I measured with higher resolution. Grains with higher intensity of 6-10 $\mathrm{nm}$ size are embedded in a matrix of uniform contrast. A detail of this granular structure and the $\mathrm{W}$ and Se elemental distribution obtained from the EDX spectra measured along the 
marked line are depicted in Figures $\mathbf{6 b}$ and $\mathbf{6 c}$. According to the profiles, the W signal rises when crossing the bright grains indicating a higher $\mathrm{W}$ content in comparison to the surroundings where the $\mathrm{W}$ and Se signals remain comparable. The oxygen signal is very low and does not experiment significant changes along the profile. The calculated average Se/W ratios are ranging from 1.0-1.3 (inside) to 1.6-1.7 (outside the bright grains). This top layer is the responsible of the good tribological behavior as demonstrated in the first part. The friction coefficient remains below 0.1 while this layer is sustaining the contact as demonstrated in the tribological part. The failure of the low friction regime occurred when entering in the second segment (II) where $\mathrm{Se} / \mathrm{W}$ is around 1.

The HRTEM study of region I shows the presence of lattice fringes, as can be observed in the representative image of Figure 7. D-spacing in the range of 6.7 to $7.6 \AA$ has been measured in different micrographs as can be seen in Figures $7 \mathrm{a}$ and $7 \mathrm{~b}$. These values are consistent with the distance between two sheets of the lamellar structure (platelet) of the hexagonal $\mathrm{WSe}_{2}$ phase (i.e. (002) spacing). This platelet structure gives rise to the appearance of packs of wires with different orientation that sometimes are curved due to the presence of defect dislocation. ${ }^{27,}{ }^{37}$ The size of the ordered $\mathrm{WSe}_{2}$ domains is around 3-6 nm which correspond to 6-10 platelets. Moreover, lattice fringes of 2.4 and 2.8 (not shown) $\AA$ have also been measured in different locations of the layer, (cf. Figure 7c) that can be associated to the planes (103) and (110) of the hexagonal $\mathrm{WSe}_{2}$ phase respectively. A d-spacing of $\sim 2.2 \AA$, measured in some small crystals of around $2 \mathrm{~nm}$ size can be assigned to the family planes (110) planes of the bcc W phase (Figures $7 b$ and $7 c$ ).

As the size of the ordered $\mathrm{WSe}_{2}$ domains $(3-6 \mathrm{~nm})$ is smaller than the size of the W-rich grains $(6-10 \mathrm{~nm})$ observed in the Z-contrast images, one can associate the matte 
zones in Figure 6a to ordered $\mathrm{WSe}_{2}$ domains and the brighter ones to the $\mathrm{W}$-rich ones. We should remember that $\mathrm{Se} / \mathrm{W}$ ratio was less than the stoichiometric 2 in the crystalline domains. While these regions will be referred to as $\mathrm{WSe}_{2}$, the $\mathrm{WSe}_{1.6}$ or $\mathrm{WSe}_{1.7}$ should be noted. This Se deficiency is not unusual and has been previously observed in sputtered metal chalcogenides (selenides or sulfides). ${ }^{19,23,27,28}$ Likewise, in the regions whereas $\mathrm{W}$ atoms are predominant, Se is present at $\mathrm{Se} / \mathrm{W}$ ratios of 1.3-1.3, and will be hereafter called as W(Se). In the HRTEM images the distances between the ordered $\mathrm{WSe}_{2}$ domains are around 6-10 nm, similar to the size of $\mathrm{W}(\mathrm{Se})$ grains measured in the Z-contrast images. These areas seem to be amorphous suggesting that an excess of $\mathrm{W}$ induces an amorphization of the $\mathrm{WSe}_{2}$ structure. A similar trend has been reported in $\mathrm{Ti}-\mathrm{WS}_{2}$ films ${ }^{38}$ when the Ti intercalation between lamellas prevented the crystalline order of the $\mathrm{WSe}_{2}$ phase. Additionally, the increase and dispersion of the interlamellar distance over the theoretical value for a stoichiometric $\mathrm{WSe}_{2}$ phase (6.49 A) support the incorporation of $\mathrm{W}$ atoms inside the structure. This increased separation between the basal planes can lead to a friction coefficient reduction by weakening the van der Walls force between the basal planes. ${ }^{27}$

As a result, one can conclude that the sliding contact area is defined as a nanocomposite formed by non-stoichiometric (Se deficient) nanocrystalline $\mathrm{WSe}_{2}$ surrounded by amorphous $\mathrm{W}(\mathrm{Se})$ grains, a-W(Se). Tungsten atoms can be thus intercalated up to certain level between the $\mathrm{WSe}_{2}$ sheets constituting the ordered $\mathrm{WSe}_{2}$ fringes detected in the HRTEM pictures. After reaching a certain level of incorporation, additional $\mathrm{W}$ atoms may be located outside the crystalline domains forming an amorphous phase $\mathrm{WSe}_{\mathrm{x}}(\mathrm{x}<2)$ and small nanocrystals of metallic $\mathrm{W}$. The presence of some tungsten oxides in specific points cannot be totally discarded as in certain 
locations 3-8 at.\% of oxygen was measured. $\mathrm{W}_{3} \mathrm{O}$ phase has been pointed out as contaminant in a previous publication. ${ }^{24}$

3.3 Friction mechanism. The contact area of wear track formed after the friction test in air was also chemically and structurally analyzed. A cross-section of the film was prepared in the form of a thin lamella by focused ion beam (FIB) technique (see scheme in Figure 8a). In Figure $\mathbf{8 b}$ a representative cross-section TEM image of the $\mathrm{WSe}_{\mathrm{x}}$ film in the contact region is shown. A thin protective Pt cap formed by two layers is covering the top surface. The contact interface presents a wavy profile due to the abrasion of surface asperities during the friction process together with some cracks perpendicular to the film surface. Figure 9 shows the comparison of the HAADF-STEM images before and after the friction tests obtained from the interface region. The nanocomposite nanostructure $\mathrm{nc}-\mathrm{WSe} \mathrm{Se}_{2} / \mathrm{a}-\mathrm{W}(\mathrm{Se})$ remains after the test but a diminution in the density of $\mathrm{W}(\mathrm{Se})$ grains in general and a certain accumulation of them in the surface in direct contact with the ball are observed.

The HRTEM images obtained for the same contact region (Figure 10) reveal an increase of the order and alignment of the $\mathrm{WSe}_{2}$ domains induced by friction. Similar phenomena have been reported in amorphous disordered carbon and metal chalcogenides used as lubricant films. ${ }^{22,37,39-41}$ The film structure under pressure and relative motion, evolves towards a situation where it minimizes the resistance to shear by alignment of the $\mathrm{WSe}_{2}$ basal planes parallel to the wear scar surface. The size of the ordered domains grows to 7-14 $\mathrm{nm}$ (corresponding to 12-16 platelets) and the measured interlamellar distances ranges between 6.8 and $7.8 \AA$. The increase of the order and alignment of the $\mathrm{WSe}_{2}$ regions is simultaneous to the decrease in density of W-rich grains commented before. This increased crystallinity of the $\mathrm{WSe}_{2}$ domains is carried 
out at the expense of a diminution of the a-W(Se) regions. However, in the topmost layer the agglomeration of $\mathrm{W}$ atoms can be explained by the consumption of the $\mathrm{WSe}_{2}$ phase in the lubrication process. The remaining $\mathrm{W}$ atoms are thus exposed to air forming tungsten oxides as $\mathrm{WO}_{3}$ identified by Raman spectroscopy in the debris particles. The presence of this metallic phase, susceptible to be easily oxidized in the contact, helps to preserve the lubricant behavior of the $\mathrm{WSe}_{2}$ phase and diminish the chemical sensitivity in ambient air.

A further study of the surface modifications induced by friction was done by using Raman confocal spectroscopic analysis on the film wear track. In Figure 11a it is shown the Raman spectrum taken at the end of the long duration test run in dry nitrogen depicted in Figure $4 \mathrm{~b}$ in comparison to that measured for the initial film. The first observation is the narrowing of the characteristic peak of W-Se bonds at $260 \mathrm{~cm}^{-1}$. The development of the associated bands at 375 and $515 \mathrm{~cm}^{-1}$ owing to $\mathrm{WSe}_{2}$ is also found. This supposes an induced structural arrangement of the $\mathrm{WSe}_{2}$ structure upon friction in agreement with the HRTEM analysis of the wear track. Figure $11 \mathrm{~b}$ presents the Raman spectra of the wear tracks as a function of the surrounding environment. This comparison allows concluding an enhanced signal of the abovementioned peaks in the sequence (atmospheric pressure, HV-1, HV-2). This indicates that in the absence of residual gas the increase of the crystallinity and alignment of the $\mathrm{WSe}_{2}$ nanocrystals are favoured. These results confirm and support the structural arrangements observed by transmission electron microscopy and the decrease of the friction coefficient by easy shear of the basal planes oriented parallel to the wear scar surface.

\section{CONCLUSIONS}


Surface engineering has enabled the design of a tailored architecture based on W-Se suitable for low friction and wear properties. This developed material decreases the oxygen and moisture sensitivity as compared to well-known solid lubricants for vacuum and space applications, such as $\mathrm{MoS}_{2}$. This functional coating is formed by a multiple architecture comprised of a bottom layer rich in W (ensuring a good mechanical support and adhesion strength to the steel substrate); an intermediate segment formed by three sub-layers (allowing a gradient transition towards the functional lubricant topmost layer) and a toplayer formed by a nanocomposite structure based on nanocrystals of $\mathrm{WSe}_{2}$ and amorphous $\mathrm{W}(\mathrm{Se})$ phase. The friction coefficient is found to be below 0.1 even in ambient air. The Raman and HRTEM analysis has proven that the tribological stresses are operative hundreds of nanometers below the contact interface although the most relevant changes affect the interfacial layer (5-10 basal planes). Advanced transmission electron microscopy evidenced that the friction process produces an increase of the crystalline domains and alignment of the $\mathrm{WSe}_{2}$ platelets parallel to the surface. The interstitial $\mathrm{W}$ is released from the interlamellar space and diffuses to the surface where it oxidizes in case of ambient air. These sacrificial $\mathrm{W}$ atoms help to prevent the oxidation of the $\mathrm{WSe}_{2}$ phase in ambient conditions supporting the improved performance of this system as a solid lubricant film with less oxygen sensitivity.

\section{- ACKNOWLEDMENTS}

The Spanish MEC (projects $\mathrm{n}^{\mathrm{o}}$ MAT2010-21597-C02-01; MAT2011-29074-C02-01 and CONSOLIDER FUNCOAT CSD2008-00023), and Junta de Andalucía P10-TEP67182 are acknowledged for financial support. 


\section{- REFERENCES}

(1) Holmberg, K.; Matthews, A.; Ronkainen, H. Coatings Tribology - Contact Mechanisms and Surface Design Tribol. Int 1998, 31, 107-120.

(2) Enomoto, T.; Sugihara, T. Improvement of anti-Adhesive Properties of Cutting Tool by nano/micro Textures and its Mechanism Procedia Eng. 2011, 19, 100-105.

(3) Veprek, S.; Veprek-Heijman, M.G.J.; Karvankova, P.; Prochazka, J. Different Approaches to Superhard Coatings and Nanocomposites Thin Solid Films 2005, $476,1-29$.

(4) Musil, J.; Vlcek, J.; Zeman, P. Hard Amorphous Nanocomposite Coatings with Oxidation Resistance above 1000 Degrees C Adv. Appl. Ceram. 2008, 107, 148-154.

(5) Muratore, C.; Voevodin, A.A. Chameleon Coatings: Adaptive Surfaces to Reduce Friction and Wear in Extreme Environments Annu. Rev. Mater. Res. 2009, $39,297-324$.

(6) Aouadi, S.M.; Paudel, Y.; Simonson, W.J.; Ge, Q.; Kohli, P.; Muratore, C.; Voevodin, A.A. Tribological Investigation of Adaptive $\mathrm{Mo}_{2} \mathrm{~N} / \mathrm{MoS}_{2} / \mathrm{Ag}$ Coatings with High Sulfur Content Surf. Coat. Technol. 2009, 203, 1304-1309.

(7) Abad, M.D.; Sanchez-Lopez, J.C. Tribological Properties of Surface-Modified Pd Nanoparticles for Electrical Contacts Wear 2013, 297, 943-951.

(8) Holmberg, K.; Matthews, A. Coatings Tribology, Tribology and Interface Engineering Series, 56, Elsevier, Amsterdam, The Netherlands, 2009.

(9) Erdemir, A. Review of Engineered Tribological Interfaces for Improved Boundary Lubrication Tribol. Int. 2005, 38, 249-256. 
(10) Fayeulle, S.; Ehni, P.D.; Singer, I.L. In Mechanics of coatings, Tribology

Series 17; Dowson D., Ed.; Elsevier, Amsterdam, The Netherlands, 1990, 129-138.

(11) Nabot, J.; Aubert, A.; Gillet, R.; Renaux, P. Cathodic Sputtering for Preparation of Lubrication Films Surf. Coat. Technol. 1990, 43/44, 629-639.

(12) Simmonds, M.C.; Savan, A.; Pflüger, E.; Van Swygenhoven, H. Mechanical and Tribological Performance of $\mathrm{MoS}_{2}$ Co-sputtered Composites Surf. Coat. Technol. 2000, 126, 15-24.

(13) Nossa, A.; Cavaleiro, A.; Carvalho, N.J.M.; Kooi, B.J.; De Hosson, J.Th.M. On the Microstructure of Tungsten Disulfide Films Alloyed with Carbon and Nitrogen Thin Solid Films 2005, 484, 389-395.

(14) Savan, A.; Pflüger, E.; Goller, R.; Gissler, W. Use of Nanoscaled Multilayer and Compound Films to Realize a Soft Lubrication Phase Within a Hard, WearResistant Matrix Surf. Coat. Technol. 2000, 126, 159-165.

(15) Watanabe, S.; Noshiro, J.; Miyake, S. Tribological Characteristics of $\mathrm{WS}_{2} / \mathrm{MoS}_{2}$ Solid Lubricating Multilayer Films Surf. Coat. Technol. 2004, 183, $347-$ 351.

(16) Oñate, J.I.; Brizuela, M.; García-Luis, A.; Braceras, I.; Viviente, J.L. Improved Tribological Behaviour of $\mathrm{MoS}_{2}$ Thin Solid Films Alloyed with WC $9^{\text {th }}$ European space mechanisms and tribology symposium, ESA special publications 2001, 480, $257-262$.

(17) Voevodin, A.A.; Zabinski, J.S. Supertough Wear-Resistant Coatings with 'Chameleon' Surface Adaptation Thin Solid Films 2000, 370, 223-231. 
(18) Gangopadhyay, S.; Acharya, R.; Chattopadhyay, A.K.; Paul, S. Composition and Structure-Property Relationship of Low Friction, Wear Resistant TiN-MoS Composite Coating Deposited by Pulsed Closed-Field Unbalanced Magnetron Sputtering Surf. Coat. Technol. 2009, 203, 1565-1572.

(19) Shtansky, D.V.; Sheveyko, A.N.; Sorokin, D.I.; Lev, L.C.; Mavrin, B.N.; Kiryukhantsev-Korneev, Ph.V. Structure and Properties of Multi-Component and Multilayer TiCrBN/WSex Coatings Deposited by Sputtering of TiCrB and $\mathrm{WSe}_{2}$ Targets Surf. Coat. Technol. 2008, 202, 5953-5961.

(20) Prasad, S.V.; McDevitt, N.T.; Zabinski, J.S. Tribology of Tungsten DisulfideNanocrystalline Zinc Oxide Adaptive Lubricant Films from Ambient to 500 Degrees C Wear 2000, 237, 186-196.

(21) Li, S.; Deng, J.; Yan, G.; Zhang, K.; Zhang, G. Microstructure, Mechanical Properties and Tribological Performance of TiSiN-WS ${ }_{2}$ Hard-Lubricant Coatings Appl. Surf. Sci. 2014, 309, 209-217.

(22) Polcar, T.; Cavaleiro, A. Review on Self-Lubricant Transition Metal

Dichalcogenide Nanocomposite Coatings Alloyed with Carbon Surf. Coat. Technol. 2011, 206, 686-695.

(23) Evaristo, M.; Polcar, T.; Cavaleiro, A. Can W-Se-C Coatings Be Competitive to W-S-C Ones? Plasma Processes Polym. 2009, 6, S92-S95.

(24) Shtansky, D.V.; Lobova, T.B.; Fominski, V.Yu.; Kulinich, S.A.; Lyasotsky, I.V.; Petrzhik, M.I.; Levashov, E.A.; Moore, J.J. Structure and Tribological Properties of $\mathrm{WSe}_{\mathrm{x}}, \mathrm{WSe}_{\mathrm{x}}, / \mathrm{TiN}, \mathrm{WSe} \mathrm{x}_{\mathrm{x}} / \mathrm{TiCN}$ and $\mathrm{WSe}_{\mathrm{x}}, / \mathrm{TiSiN}$ Coatings Surf. Coat. 
Technol. 2004, 183, 328-336.

(25) Fominski, V.Yu.; Nevolin, V.N.; Romanov, R.I.; Titov, V.I.; Scharff, W.

Tribological Properties of Pulsed Laser Deposited WSex(Ni)/DLC Coatings Tribol.

Lett. 2004, 17, 289-394.

(26) Kubart, T.; Polcar, T.; Kopecky, L.; Novak, R.; Novakova, D. Temperature

Dependence of Tribological Properties of $\mathrm{MoS}_{2}$ and $\mathrm{MoSe}_{2}$ Coatings Surf. Coat.

Technol. 2005, 193, 230-233.

(27) Hu, J.J.; Zabinski, J.S.; Bultman, J.E.; Sanders, J.H.; Voevodin, A.A. Structure

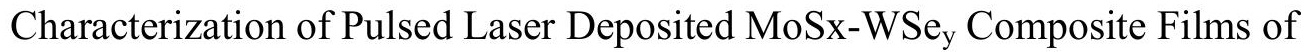

Tribological Interests Tribol. Lett. 2006, 24, 127-135.

(28) Fominski, V.Yu.; Gregoriev, S.N.; Celis, J.P.; Romanov, R.I.; Oshurko, V.B.

Structure and Mechanical Properties of W-Se-C/Diamond-Like Carbon and W-

Se/Diamond-Like Carbon Bi-Layer Coatings Prepared by Pulsed Laser Deposition

Thin Solid Films 2012, 520, 6476.

(29) Gregoriev, S.N.; Fominski, V.Yu.; Gnedovets, A.G.; Romanov, R.I.

Experimental and Numerical Study of the Chemical Composition of WSex Thin

Films Obtained by Pulsed Laser Deposition in Vacuum and in a Buffer Gas

Atmosphere Appl. Surf. Sci. 2012, 258, 7000-7007.

(30) Guettari, N.; Ouerfelli, J.; Bernède, J.C.; Khelil, A.; Pouzet, J.; Conan, A.

Photoconductive WSe2 Thin Films Obtained by Solid State Reaction in the

Presence of a Thin Nickel Layer Mater. Chem. Phys. 1998, 52, 83-88.

(31) Chiritescu, C.; Cahill, D.G.; Nguyen, N.; Johnson, D.; Bodapati, A.; Keblinski, P.; Zschack, P. Ultralow Thermal Conductivity in Disordered, Layered $\mathrm{WSe}_{2}$ 
Crystals Science 2007, 315, 351-353.

(32) Jamison, W.E.; Cosgrove, S.L. Friction Characteristics of Transition-Metal Disulfides and Diselenides ASLE Trans. 1970, 14, 62-72.

(33) Bhushan, B.; Gupta, B.K. Handbook of Tribology-Materials, Coatings and Surface Treatments, McGraw-Hill, Inc., USA, 1991, 51-66.

(34) Polcar, T.; Evaristo, M.; Stueber, M.; Cavaleiro, A. Mechanical and Tribological Properties of Sputtered Mo-Se-C Coatings Wear 2009, 266, 393-397.

(35) Dominguez-Meister, S.; Justo, A.; Sanchez-Lopez, J.C. Synthesis and Tribological Properties of WSex Films Prepared by Magnetron Sputtering Mat. Chem. Phys. 2013. 142, 186-194.

(36) Donnet, C. ; Le Mogne, T. ; Ponsonnet, L.; Belin, M. ; Grill, A. ; Patel, V. ; Jahnes, C. The Respective Role of Oxygen and Water Vapor on the Tribology of Hydrogenated Diamond-Like Carbon Coatings Tribol. Lett. 1998, 4, 259-265.

(37) Polcar, T.; Evaristo, M.; Colaco, R.; Sandu, C.S.; Cavaleiro, A. Nanoscale triboactivity: The Response of Mo-Se-C Coatings to Sliding Acta Mater. 2008, 56, $5101-5111$

(38) Scharf, T.W.; Rajendran, A.; Banerjee, R.; Sequed, F. Growth, Structure and Friction Behavior of Titanium Doped Tungsten Disulphide (Ti-WS2)

Nanocomposite Thin Films Thin Solid Films, 2009. 517, 5666-5675.

(39) Sánchez-López, J.C.; Erdemir, A.; Donnet, C.; Rojas, T.C. Friction-Induced Structural Transformations of Diamondlike Carbon Coatings under Various Atmospheres Surf. Coat. Technol. 2003, 163-164, 444-450. 
(40) Hu, J.J.; Wheeler, R.; Zabinski, J.S.; Shade, P.A.; Shiveley, A.; Voevodin,

A.A. Transmission Electron Microscopy Analysis of Mo-W-S-Se Film Sliding Contact Obtained by Using Focused Ion Beam Microscope and In Situ

Microtribometer Tribol. Lett. 2008, 32, 49-57.

(41) Scharf, T.W.; Goeke, R.S.; Kotula, P.G.; Prasad, S.V. Synthesis of Au-MoS2

Nanocomposites: Thermal and Friction-Induced Changes to the Structure ACS Appl.

Mater. Interfaces 2013, 5, 11762-11767. 


\section{FIGURE CAPTIONS}

Figure 1. Evolution of the friction coefficient of $\mathrm{WSe}_{\mathrm{x}}$ film vs. number of sliding cycles for ambient air $\left(10^{3} \mathrm{mbar}\right), \mathrm{HV}-1\left(4 \times 10^{-7} \mathrm{mbar}\right)$ and $\mathrm{HV}-2\left(3.5 \times 10^{-8} \mathrm{mbar}\right)$. The average friction values obtained for the three conditions are $0.04 \pm 0.02$ (HV1), $0.05 \pm 0.03$ (HV2) and $0.08 \pm 0.02$ (Patm).

Figure 2. Evolution of the friction coefficient of $\mathrm{WSe}_{\mathrm{x}}$ film vs. number of sliding cycles at variable pressure in the tribometer chamber.

Figure 3. Influence of the surface modification before stabilisation of the friction coefficient. The ball rubbed in the first part is lifted up and placed on a new fresh surface.

Figure 4. Long duration friction tests carried out in dry nitrogen until sudden rise in COF value (a) and just before it (b).

Figure 5. a) TEM cross-section of the $\mathrm{WSe}_{\mathrm{x}}$ coating displaying the gradient functional layered architecture; b) STEM/HAADF variation and atomic composition across the profile marked in Figure 5a; c) Se/W ratio for the different sublayers observed in Figure $5 \mathrm{a} ; \mathrm{d})$ Variation of the applied negative voltage to the substrates during the growth time in hours.

Figure 6. a) Z-contrast image of the top-most layer; b) Detail at higher magnification showing two bright grains; c) intensity of $\mathrm{W}$ and Se signals measured by EDX along the marked profile of Figure $6 b$.

Figure 7. (a), (b) and (c) HRTEM micrographs showing the different interplanar distances found in the $\mathrm{WSe}_{\mathrm{x}}$ samples. The digital diffraction patterns obtained from the marked squares are depicted as insets. 
Figure 8. a) Scheme of the wear track and FIB cross-section; b) TEM image of the cross-section obtained by FIB.

Figure 9. Comparison of the HAADF-STEM images before (a) and after the friction tests (b) obtained from the interface contact region.

Figure 10. (a) and (b) HRTEM images obtained from the contact region. An increase ordering and alignment of the basal planes is marked inside the squares. The digital diffraction patterns obtained from the marked squares are depicted as insets.

Figure 11. a) Raman spectra obtained from the wear track after long duration tribological test run in dry nitrogen in comparison with the initial one; b) Raman spectra measured from the wear track obtained under atmospheric, $\mathrm{HV}-1$ and $\mathrm{HV}-2$ environments. 


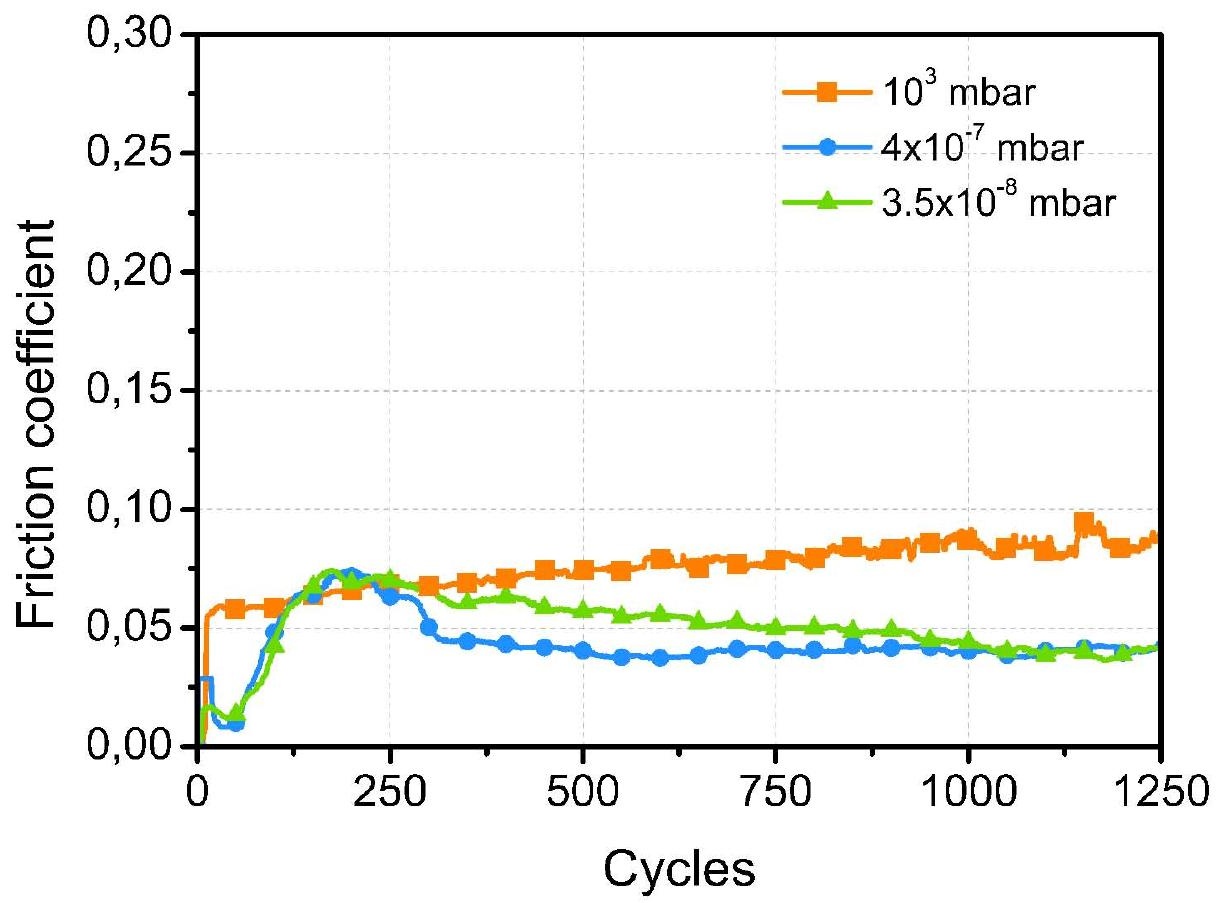




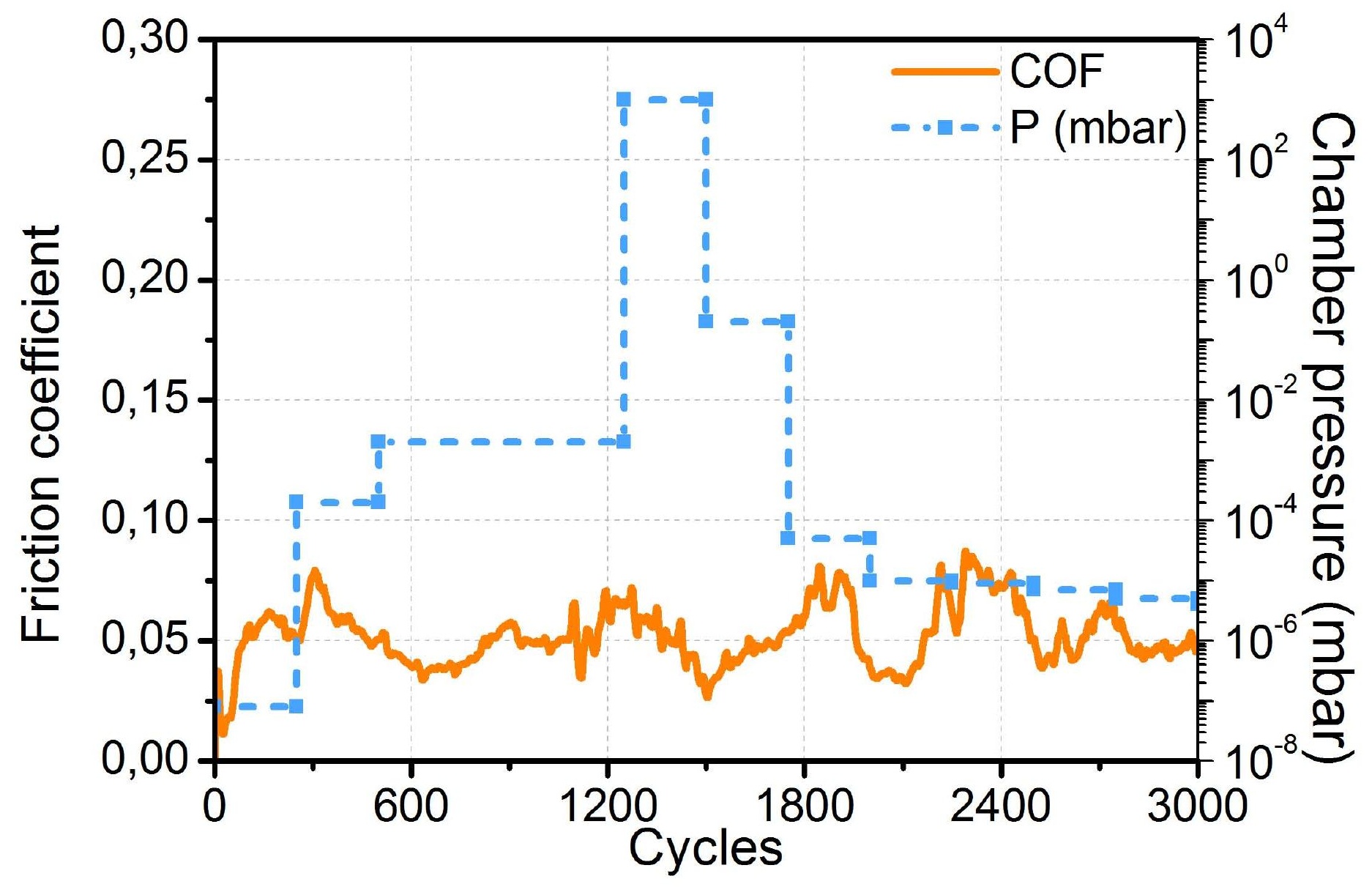




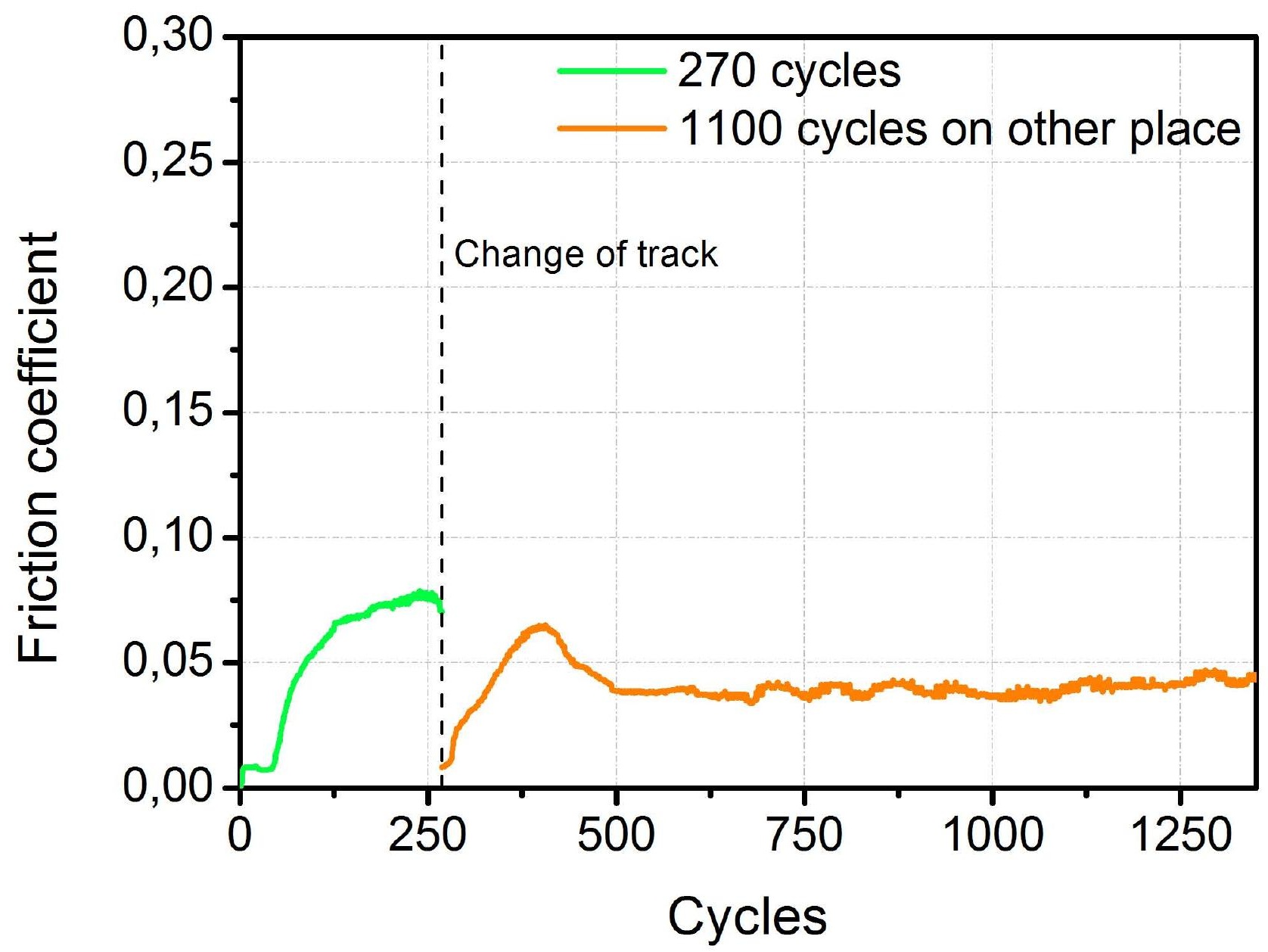



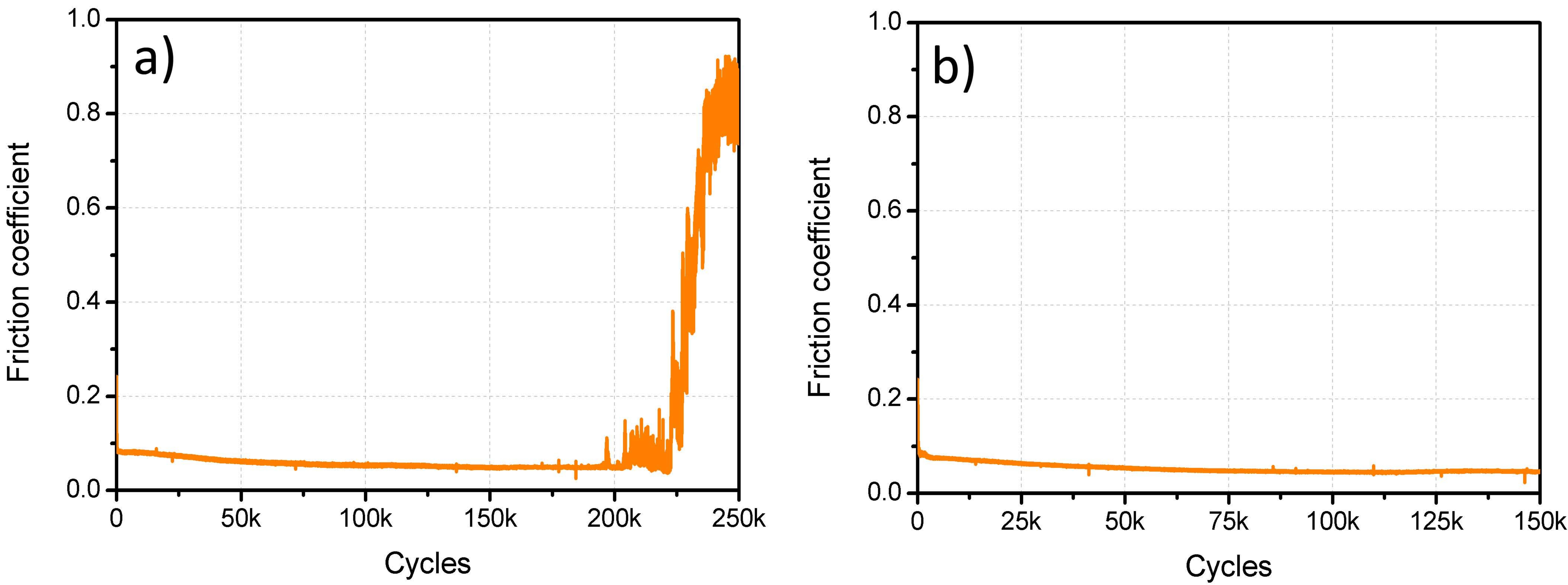
a)

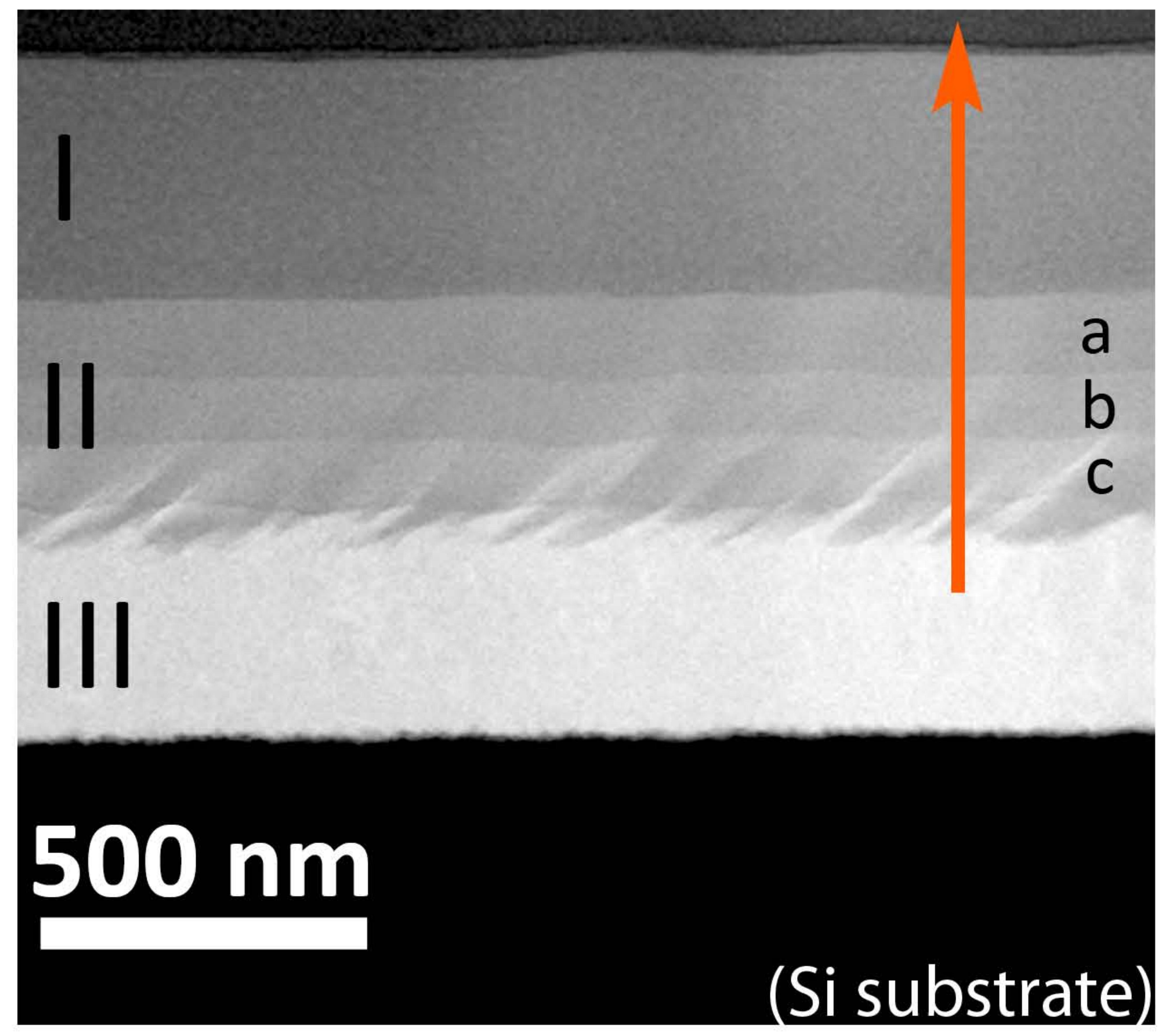

c)

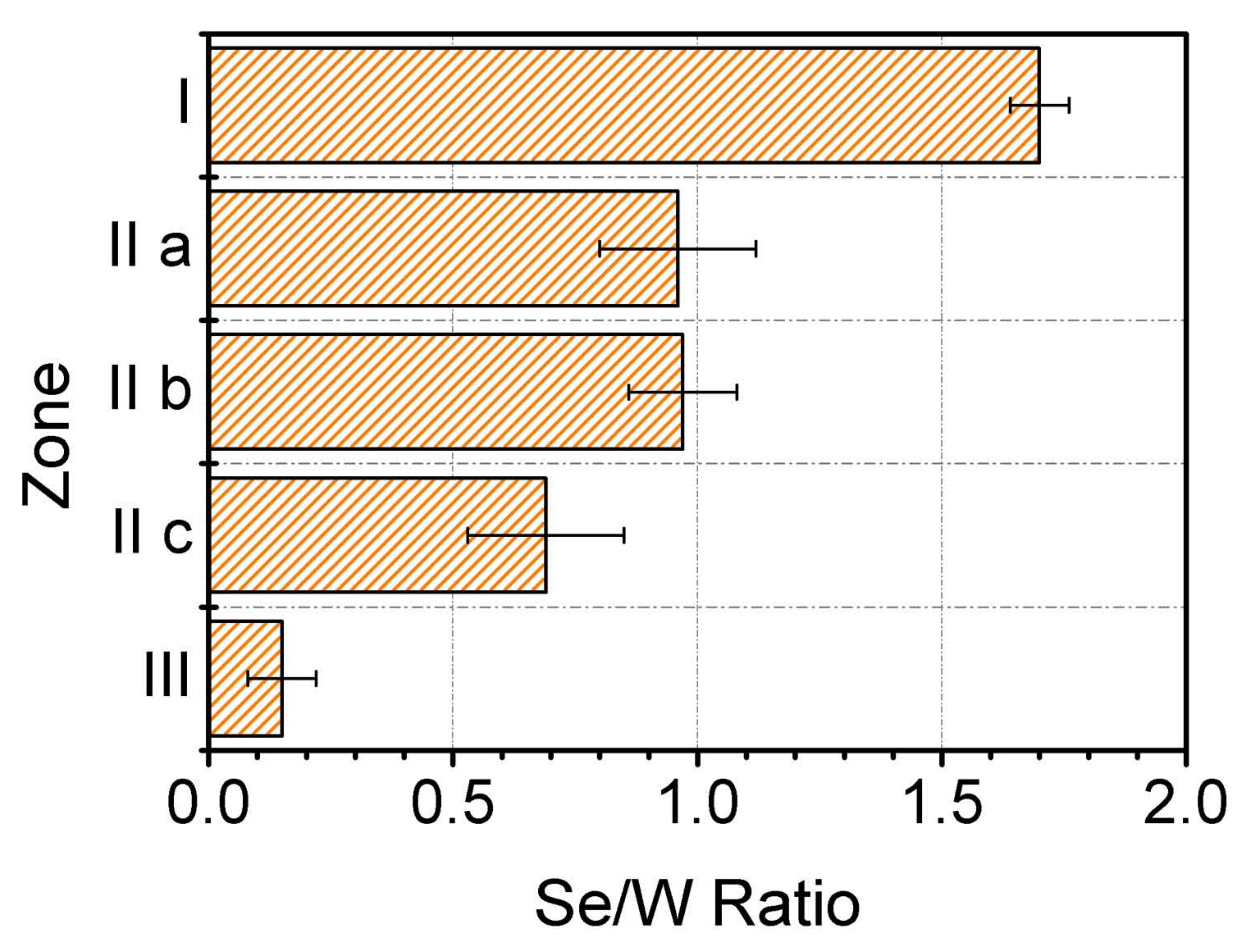

b)

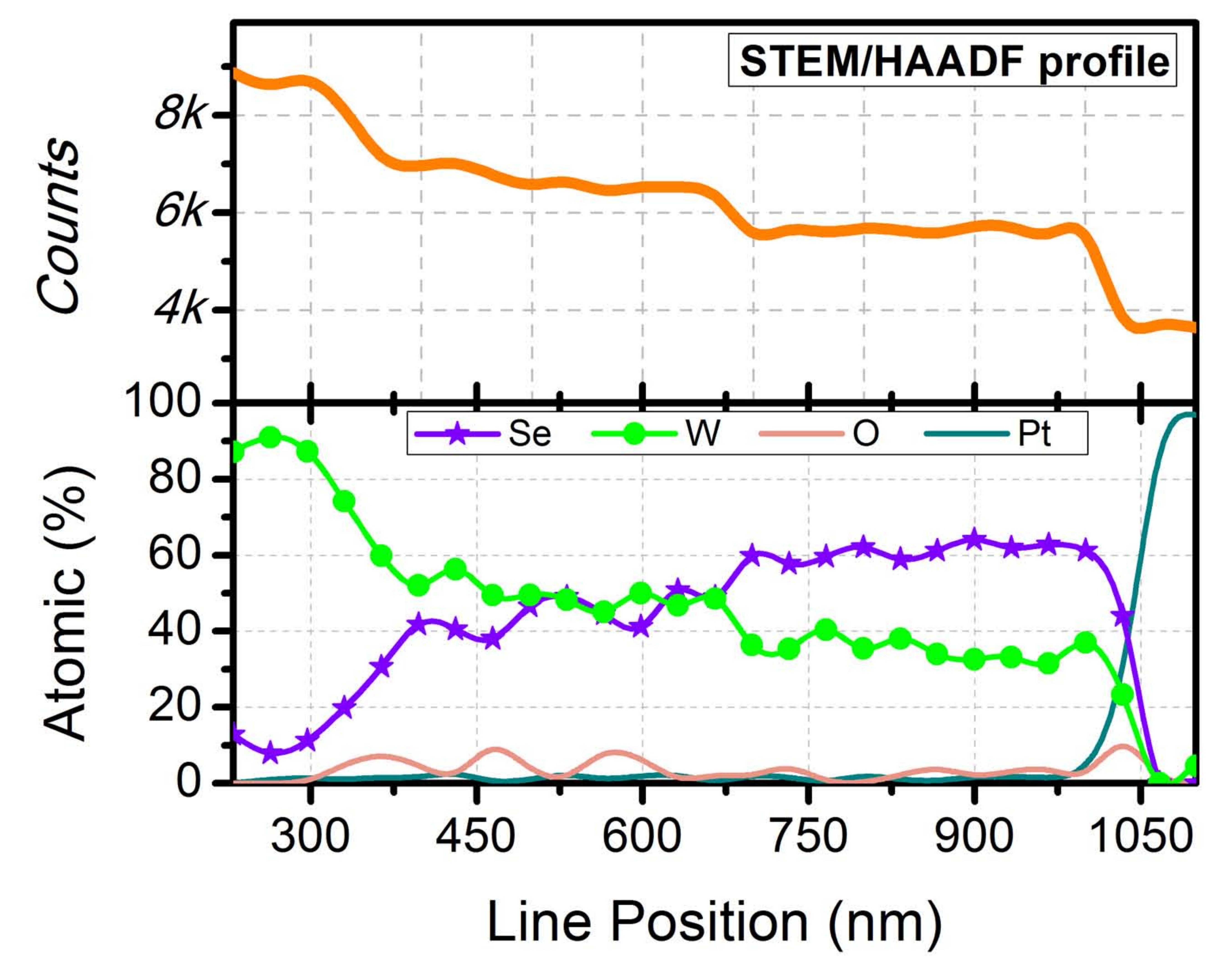

d)

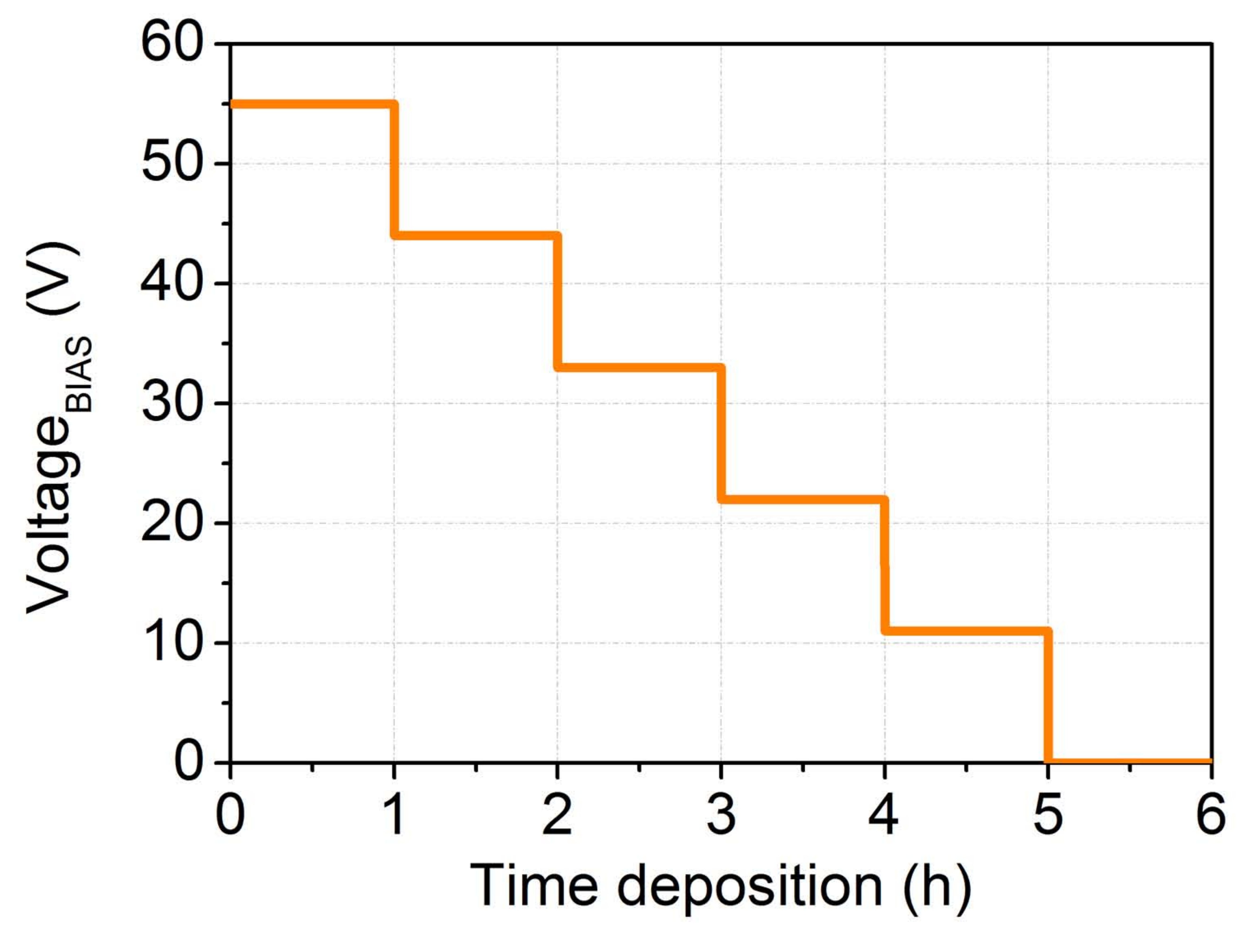




\section{a)}

\section{$100 \mathrm{~nm}$}

b)

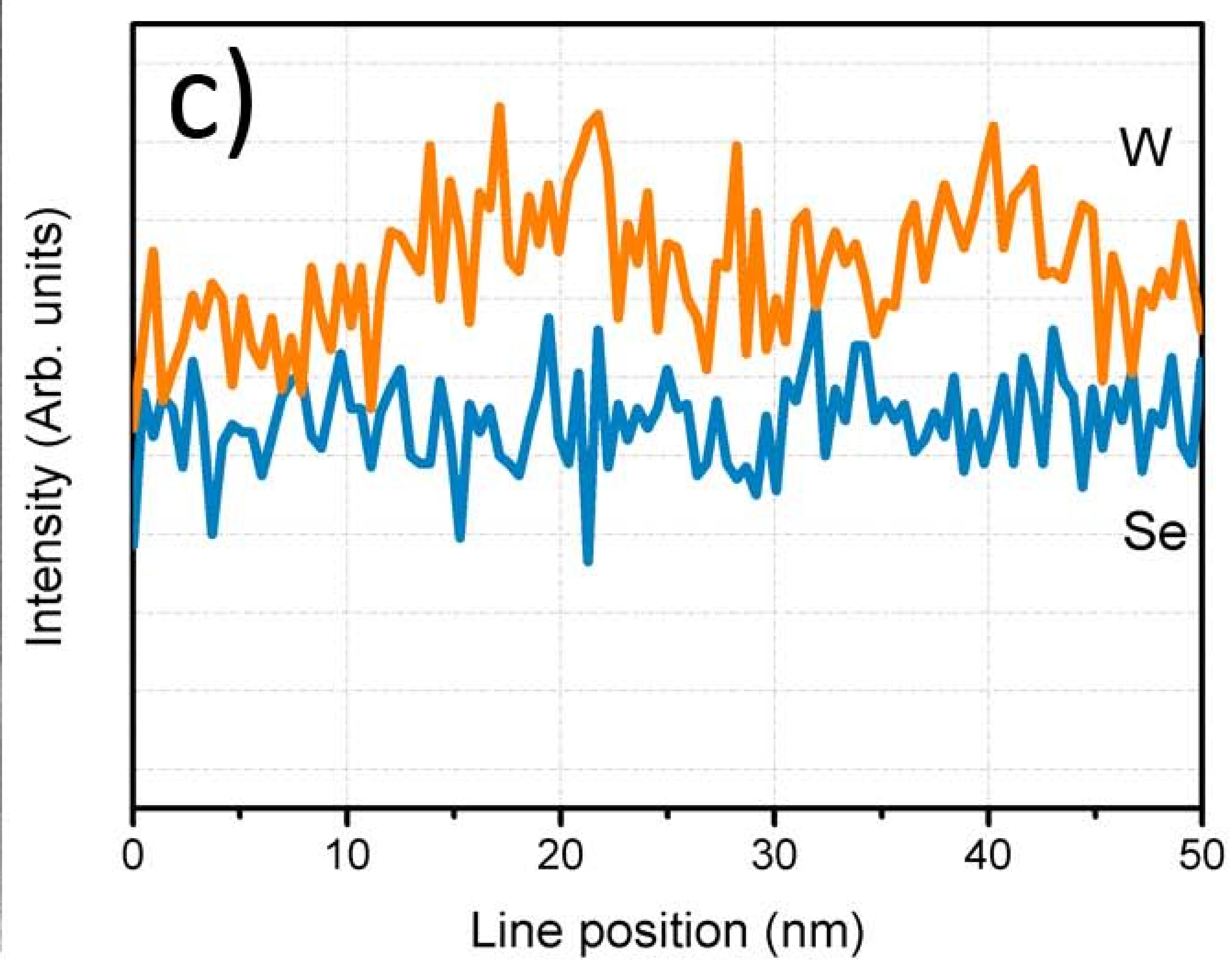




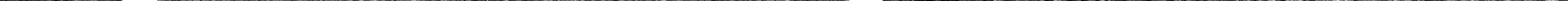
$\frac{20 \mathrm{hm}}{2}$

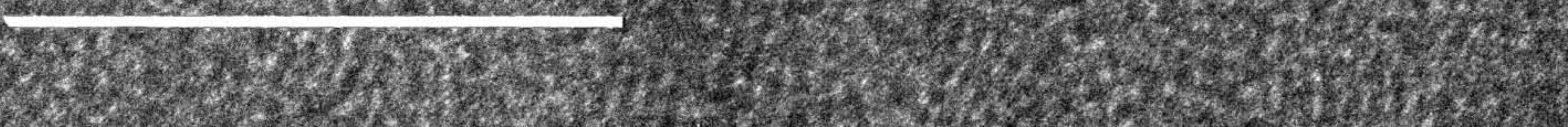
Trtes , 

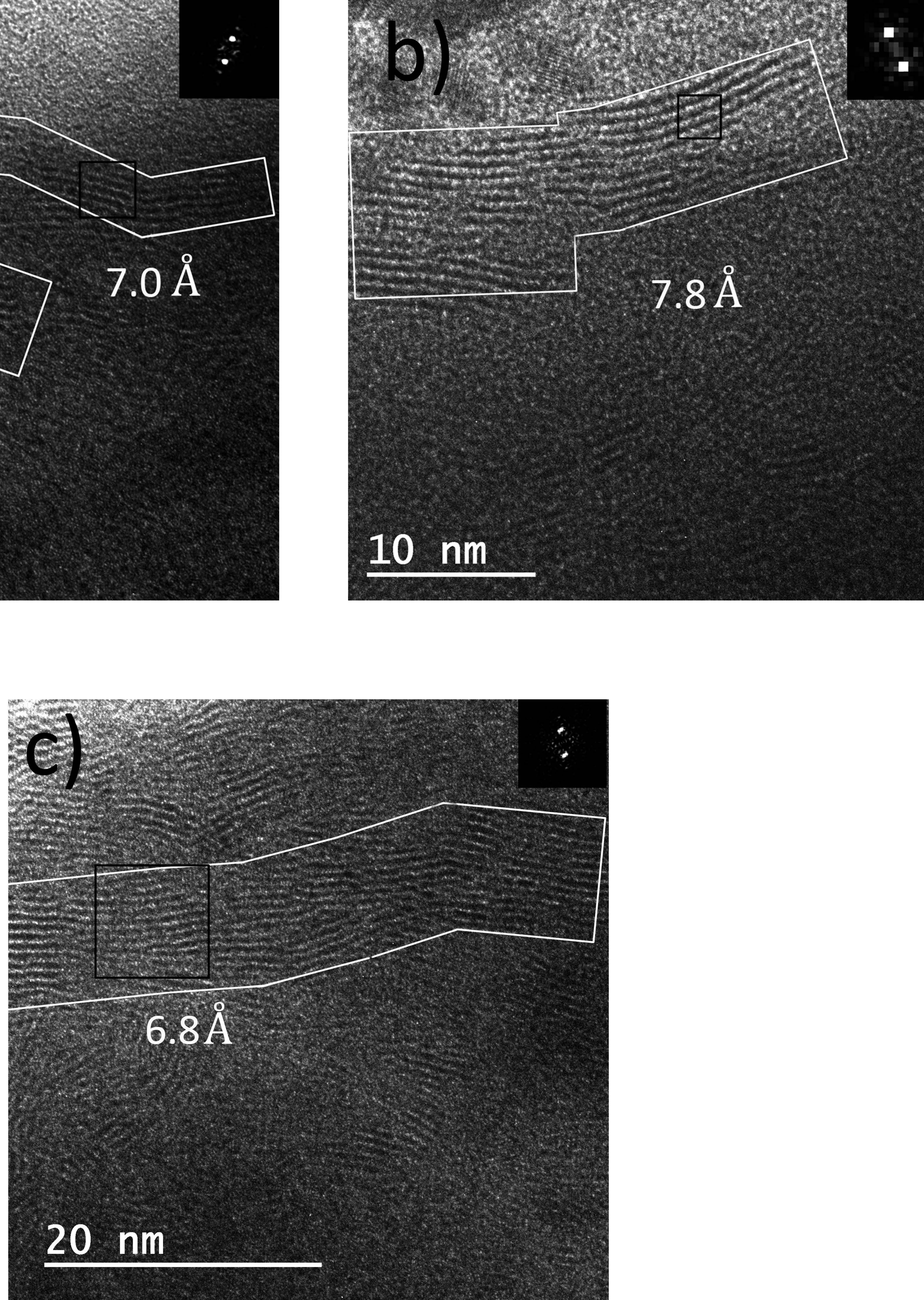

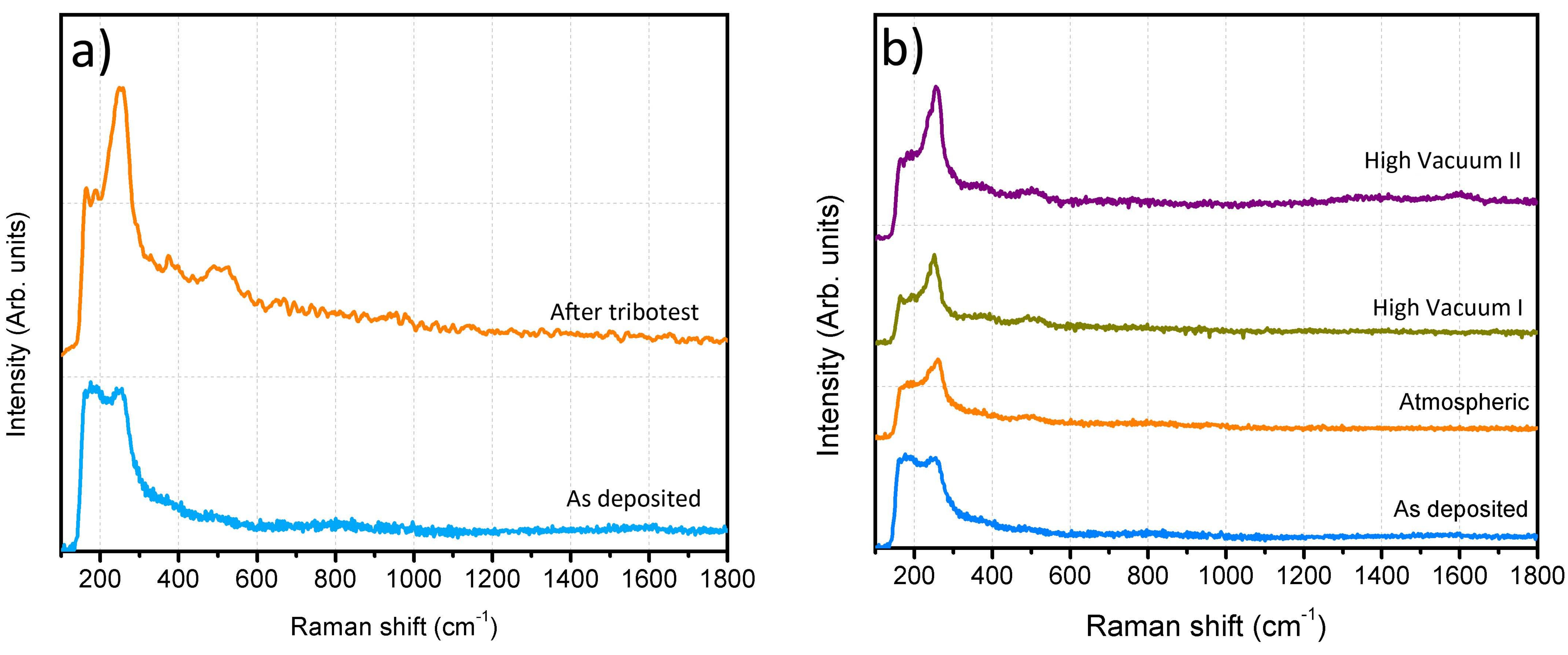


\section{Tailored Structure}

\section{$500 \mathrm{~nm}$}

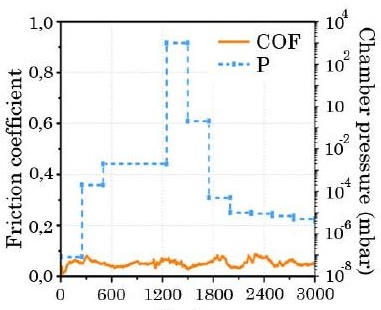

Cycles 